\title{
Mikrotomograficzna identyfikacja wad powłok napawanych
}

\author{
Defects identyfication of padding coatings \\ using X-Ray Mikrotomography method
}

\section{Streszczenie}

W artykule przedstawiono wykorzystanie metody tomografii komputerowej CT (ang. Computed Tomography) do oceny powłok napawanych. Do otrzymania napoin wykorzystano metodę napawania elektrodą nietopliwą w osłonie gazowej TIG (ang. tungsten inert gas) z wykorzystaniem stopowych drutów do napawania powłok odpornych na zużycie o nazwach handlowych: EL-500 HB, EL-600 HB, EL-650 HB. Scharakteryzowano typowe wady wykonanych napoin oraz wpływ rodzaju drutu na koncentrację wad. Najmniejszy średni procentowy udział wad w stosunku do powierzchni całkowitej otrzymano dla napoiny EL- 600 HB, który wyniósł $1,5 \%$.

Słowa kluczowe: napawanie; powłoka napawana; tomografia komputerowa CT; wady i niezgodności spawalnicze

\begin{abstract}
The paper presents the use of Computed Tomography (CT) for the evaluation of padding coatings. The method used to obtain a padding weld is pad welding with tungsten inert gas (TIG) using alloy wires for pad welding of wear resistant layers under the trade names: EL-500 HB, EL-600 HB, EL-650 HB. It characterizes the typical defects of obtained padding welds and the impact of the type of wire on the concentration of defects. The smallest average percentage of defects in relation to the overall surface is observed for the padding weld EL-600 HB, which amounts to $1.5 \%$.
\end{abstract}

Keywords: pad welding; padding coating; computed tomography; welding defects and inconsistencies

\section{Wstęp}

Główną przyczyną uszkodzeń części maszyn powodujących ponoszenie dużych kosztów przez przedsiębiorstwa jest zużycie powierzchni roboczych. Obecnie jedną z najczęściej stosowanych metod regeneracji części maszyn jest napawanie, czyli nakładanie warstwy ciekłego metalu na regenerowany obiekt [1]. Korzystne efekty techniczne i ekonomiczne regeneracji i modyfikacji powierzchni metodą napawania, w szczególności tam gdzie wymagana jest duża odporność na zużycie i korozję, spowodowały dynamiczny rozwój technologii urządzeń i materiałów stosowanych do napawania. Obecnie stosowane techniki spawalnicze pozwalają na przeprowadzenie napraw praktycznie każdej uszkodzonej lub zużytej części na drodze spawania lub napawania. Nowoczesnymi i często wykorzystywanymi materiałami do napawania są elektrody lub druty lite i proszkowe (rdzeniowe). Obecnie stosowane materiały otrzymywane są na bazie $\mathrm{Fe}, \mathrm{Ni}, \mathrm{Co}, \mathrm{Ti}$ z dodatkami różnych pierwiastków chemicznych, między innymi takich jak: Si, Cr, B, Mn, V, Mo, $\mathrm{W}, \mathrm{Nb}$ wpływających na ich właściwości mechaniczne, tribologiczne, korozyjne [2:4].

W praktyce przemysłowej do wykrywania wad i niezgodności wykorzystywane są te same metody co przy badaniach połączeń spawanych. Nowoczesna metoda tomografii kompute- rowej, ze względu na swoje zalety, jest coraz częściej dostępna i stosowana również w przemyśle w tym w spawalnictwie. Tomografia komputerowa CT (ang. Computed Tomography) jest rodzajem spektroskopii rentgenowskiej. Wykorzystywana jest jako metoda diagnostyczna pozwalająca na uzyskanie obrazów warstwowych badanych napoin [5]. Wykorzystuje ona złożenie projekcji obiektu, wykonanych z różnych kierunków, do utworzenia obrazów przekrojowych (2D) i przestrzennych (3D) [6]. W związku z tym, tomografia komputerowa znalazła zastosowanie w spawalnictwie do nieniszczących badań połączeń spawanych oraz powłok napawanych. Celem badań w prezentowanej pracy jest określenie jakościowego i ilościowego występowania wad napoin, rozmieszczenie tych wad i ich wielkość [7]. Tomografia komputerowa CT jest metodą dokładniejszą od dotychczas stosowanych metod rentgenowskich. Ograniczeniami są wysoki koszt urządzeń, mobilność i wielkość przestrzeni pomiarowej [8].

\section{Materiały oraz metody}

Obiektem badań były regeneracyjne powłoki napawane, otrzymane metodą TIG (ang. Tungsten Inert Gas). Jest to

Dr inż. Jerzy Józwik, dr inż. Krzysztof Dziedzic - Politechnika Lubelska; mgr inż. Wojciech Wierzba - Rywal-RHC Sp. z o.o. Autor korespondencyjny/Corresponding author. j.jozwik@pollub.pl 
Tablica I. Parametry fizykochemiczne drutów do napawania

Table I. Physicochemical parameters of wires for pad welding

\begin{tabular}{|c|c|c|c|c|}
\hline Symbol & Specyfikacja & Skład & Twardość & Gaz osłonowy/biegunowość \\
\hline EL-500 HB & $\begin{array}{c}\text { DIN 8555: } \\
\text { M/WSG 2GZ-500 } \\
\text { Werkstiff Nr.: } 1.8425 \\
\text { EN 14700: S Fe } 2\end{array}$ & $\begin{array}{l}\text { C: } 1,15 \\
\text { Mn: } 1,95 \\
\text { Cr: } 1,90\end{array}$ & $\begin{array}{l}\text { Brinell } 530 \\
\text { Rockwell } 52\end{array}$ & $\begin{array}{l}\text { WIG: (ISO 14175) I1 (= -) } \\
\text { MSG: (ISO 14175) M1-M3 (=+) }\end{array}$ \\
\hline EL-600 HB & $\begin{array}{c}\text { EN 14700: S Fe } 8 \\
\text { DIN 8555: } \\
\text { M/WSG 6-GZ-60 } \\
\text { Werkstiff Nr.:1.4718 }\end{array}$ & $\begin{array}{l}\text { C: } 0,45 \\
\text { Mn: } 0,40 \\
\text { Cr: } 9,20 \\
\text { Si: } 3,00\end{array}$ & Rockwell 59 & $\begin{array}{l}\text { WIG: (ISO 14175) I1 (= -) } \\
\text { MSG: (ISO 14175) M1-M3 (= +) }\end{array}$ \\
\hline EL-650 HB & $\begin{array}{l}\text { EN 14700: S Fe } 3 \\
\text { DIN 8555: } \\
\text { WSG 3-GZ-60 T }\end{array}$ & $\begin{array}{c}\text { C: } 0,4 ; \text { Si: } 1,1 \\
\text { Mn: } 0,4 ; \text { Cr: } 5,30 \\
\text { Mo: } 1,4 ; \text { V: } 0,35 \\
\text { W: } 1,35\end{array}$ & $\begin{array}{l}\text { Brinell 570-660 } \\
\text { Rockwell 57-60 }\end{array}$ & $\begin{array}{c}\text { WIG: (ISO 14175) I1 (= -) } \\
\text { MSG: (ISO 14175) M1-M3 (= +) }\end{array}$ \\
\hline
\end{tabular}

metoda spawania (napawania) elektrodą nietopliwą w osłonie gazowej Do otrzymania powłok wykorzystano nowoczesne lite druty spawalnicze do napawania, charakteryzujące się wysokimi właściwościami mechanicznymi oznaczone jako: EL-500 HB, EL-600 HB, EL-650 HB marki Most. Materiały te stosowane są do regeneracji lub modyfikacji powierzchni roboczych elementów maszyn i narzędzi, od których wymagane są dobre właściwości mechaniczne i wysoka odporność na zużycie. Parametry fizykochemiczne drutów do napawania zawarto $\mathrm{w}$ tablicy $\mathrm{I}$.

\section{a)}

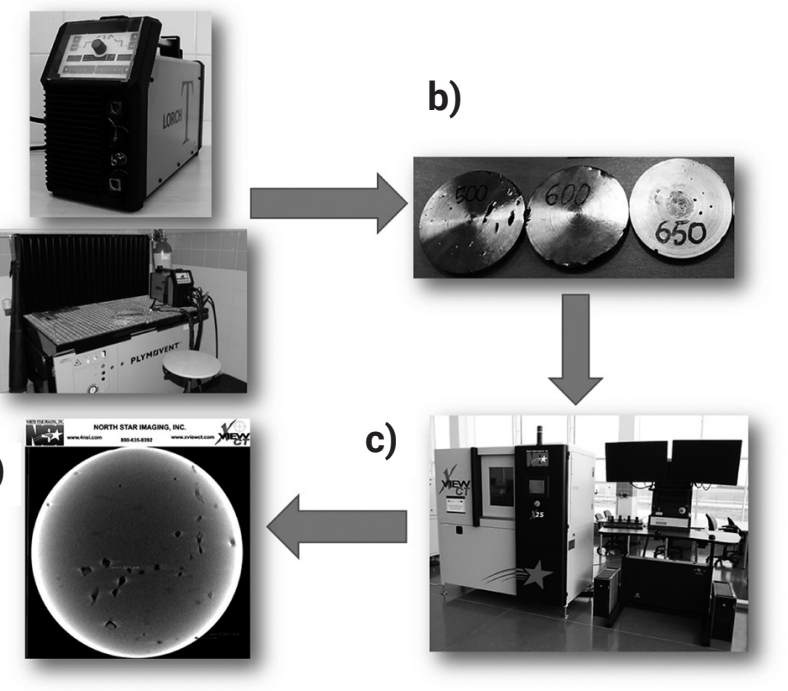

Rys. 1. Schemat badań: a) stanowisko spawalnicze T 300 AC/DC ControlPro LORCH, b) próbki po obróbce tokarskiej, c) system tomografii komputerowej X25 (North Star Imaging, d) zobrazowanie RTG napoiny

Fig. 1. Scheme of assessment: a) inverter machine T $300 \mathrm{AC} / \mathrm{DC}$ ControlPro LORCH, b) the sample, c) computed tomography system X25 (North Star Imaging, d) X-ray image

Proces napawania przeprowadzono na stanowisku technologicznym zaprezentowanym na rysunku 1 a. Stanowisko składa się z inwertora spawalniczego T 300 AC/DC ControlPro LORCH. Parametry technologiczne procesu napawania zastosowano zgodnie z tablica I dla wszystkich wykorzystywanych drutów. Przyjęto natężenie prądu na poziomie $80 \mathrm{~A}$, napięcie $18 \mathrm{~V}$, biegunowość dodatnia. Zastosowanym gazem osłonowym był Argon o czystości 99,9\%.

Proces napawania prowadzono na powierzchni czołowej wałka ze stali C 45 o średnicy $60 \mathrm{~mm}$ i wysokości
$50 \mathrm{~mm}$. Nakładano cztery warstwy każdej napoiny, co według danych literaturowych pozwoliło uzyskać skład zbliżony do składu wykorzystywanych drutów. Po wykonaniu napoiny na całej powierzchni czołowej prowadzono obróbkę tokarską celem nadania próbce określonych cech geometrycznych $(\$ 50 \mathrm{~mm}, \mathrm{I}=20 \mathrm{~mm})$. Toczenie prowadzono zarówno na powierzchni czołowej jak również walcowej. Następnie próbki odcięto od pozostałej części wałka zachowując wysokość próbki h=5 mm, uwzgledniającej naddatek na obróbkę szlifierską na poziomie $0,3 \mathrm{~mm}$ (rys. 1 b). Proces szlifowania prowadzono na szlifierce do płaszczyzn firmy KENT. Po obróbce szlifierskiej próbkom nadano ostateczne parametry geometryczne $\Phi 50 \times 5 \mathrm{~mm}$. Oceny nieciągłości struktury wewnętrznej oraz wad wewnętrznych dokonywano z wykorzystaniem tomografu komputerowego X25 (North Star Imaging) zaprezentowanego na rysunku $1 \mathrm{c}$. Urządzenie X-ray posiada źródło Hamamatsu L12161-07, a podstawowe parametry elektryczne to: napięcie - $150 \mathrm{kV}$, prąd - $500 \mu \mathrm{A}$. Badania polegały na skierowaniu na badany obiekt wiązki promieniowania $X$ i rejestrację jego natężenia po drugiej stronie - na panelu detektorów. Obraz RTG napoiny przedstawiono na rysunku 1d Złożenie obiektu (modelowanie) pozwoliło na szczegółową lokalizację i analizę wad wewnętrznych wykonanych napoin.

\section{Otrzymane rezultaty i dyskusja}

W oparciu o przeprowadzone badania eksperymentalne napawania regeneracyjnego dokonano oceny ilościowej wad wewnętrznych wykonanych napoin. Analizowano rozłożenie i koncentrację wad wewnętrznych każdej napoiny. Badania realizowano w kolejnych warstwach dyskretnych, położonych odpowiednio od powierzchni czołowej w odległości: $\sim 0 \mathrm{~mm}$, $1 \mathrm{~mm}, 2 \mathrm{~mm}, 3 \mathrm{~mm}, 4 \mathrm{~mm}, \sim 5 \mathrm{~mm}$. Graficzną prezentację rozłożenia i koncentracji wad wewnętrznych napoiny EL-650 HB w kolejnych warstwach położonych odpowiednio od powierzchni czołowej zaprezentowano na rysunku 2. W napoinie EL-500 HB zaobserwowano występowanie wad wewnętrznych w postaci porów. Ich liczba zmniejsza się w pobliżu powierzchni i w warstwie od strony materiału rodzimego. Procedurę wyznaczania koncentracji porów i wad wewnętrznych napoin zrealizowano z wykorzystaniem specjalistycznego graficznego środowiska programowego (rys. 3).

$\mathrm{Na}$ rysunku 3 przedstawiono metodykę postępowania przy określaniu wyniku obliczeń procentowego udziału porów (ich powierzchni) w stosunku do powierzchni całkowitej.

Rysunek 3a przedstawia zdjęcie rentgenowskie w zada- 

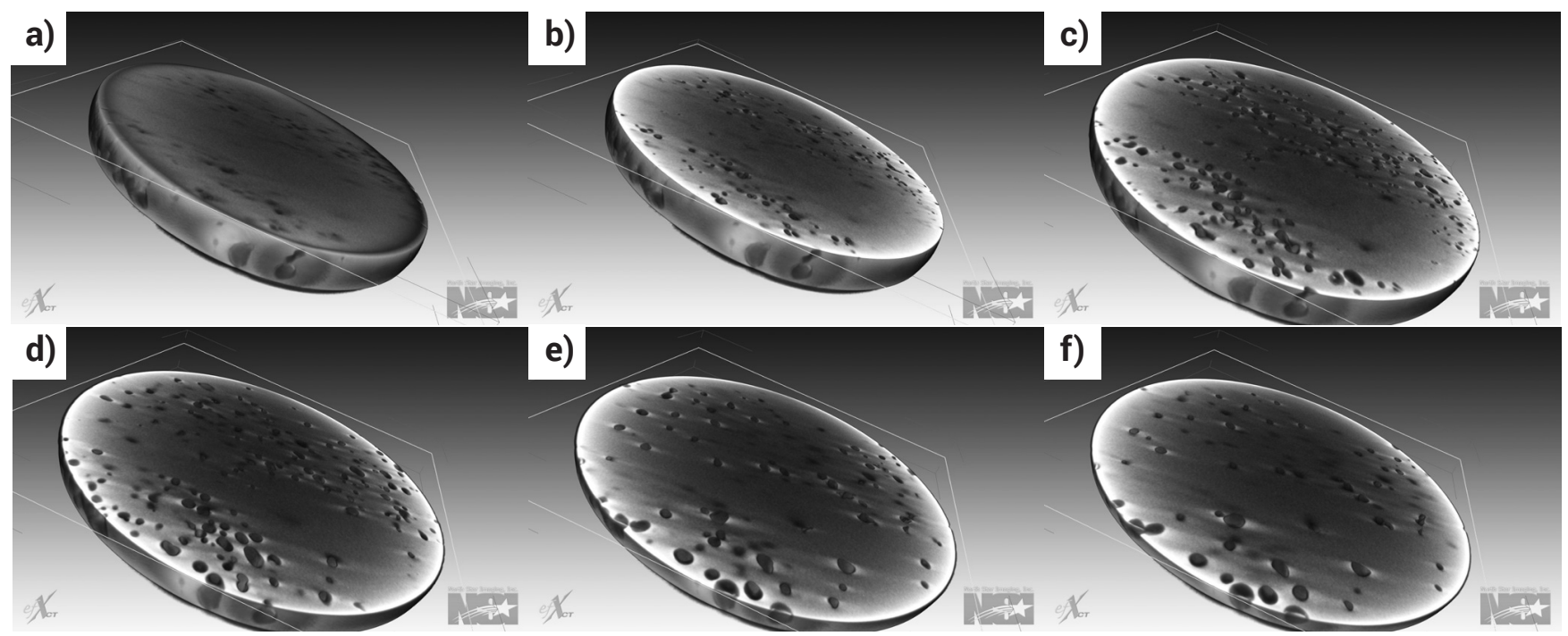

e)
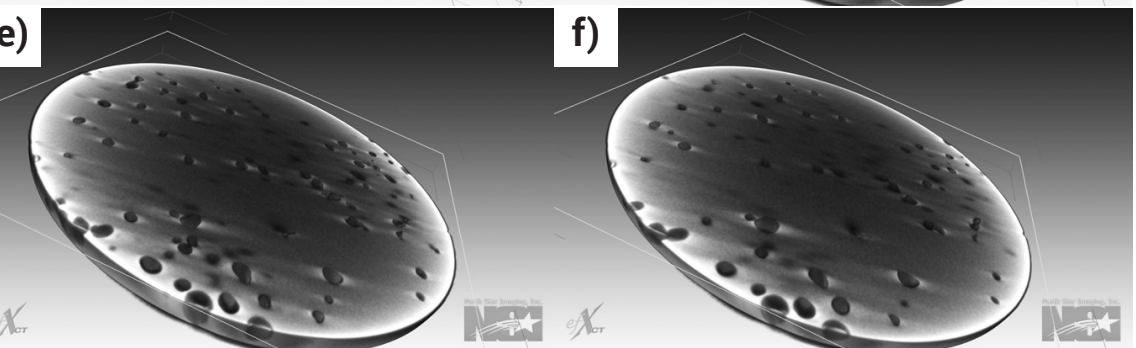

Rys. 2. Rozłożenie i koncentrację wad dla napoiny EL-650 HB w odległościach: a) 0 mm, b) $1 \mathrm{~mm}$, c) $2 \mathrm{~mm}$, d) $3 \mathrm{~mm}$, e) $4 \mathrm{~mm}$, f) $\sim 5 \mathrm{~mm}$ Fig. 2. The distribution and concentration of defects in the padding weld EL-500 HB at distances: a) $\sim 0 \mathrm{~mm}$, b) $1 \mathrm{~mm}$, c) $2 \mathrm{~mm}$, d) $3 \mathrm{~mm}, \mathrm{e}$ ) $4 \mathrm{~mm}, \mathrm{f}) \sim 5 \mathrm{~mm}$
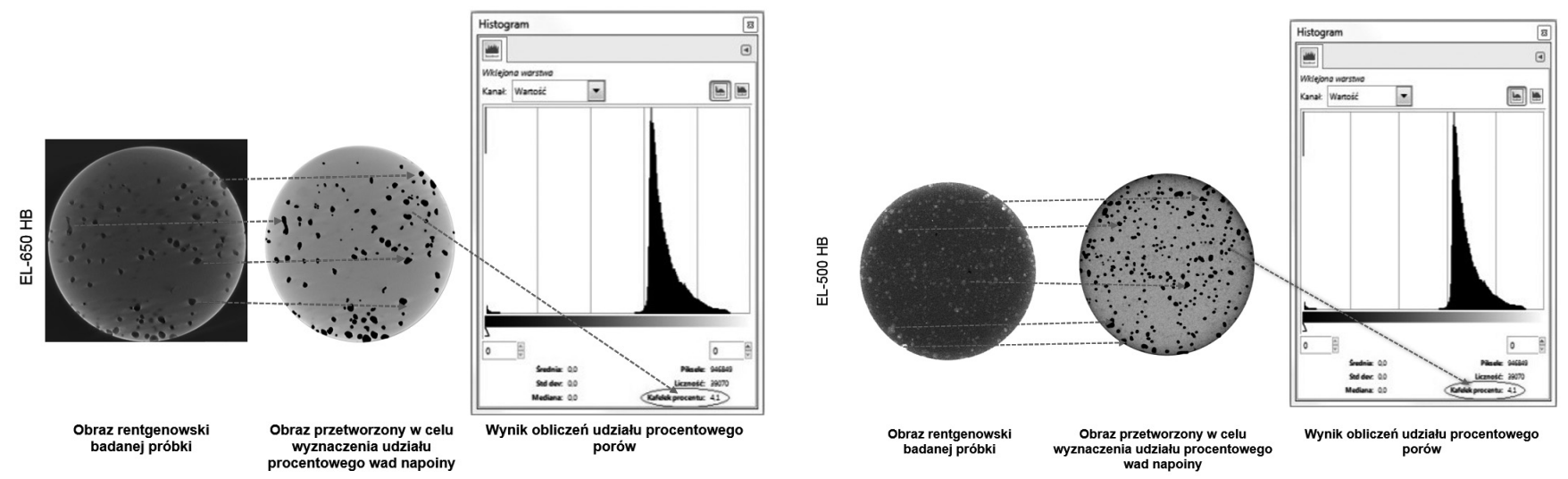

Rys. 3. Procedura wyznaczania koncentracji porów i wad wewnętrznych napoin z wykorzystaniem środowiska programowego dla napoin EL-500 HB i EL-650 HB gdzie: a) zdjęcie rentgenowskie w zadanym przekroju b) przetworzony obraz w wyniku przypisania poszczególnym kolorom powierzchni binarnie koloru w środowisku programowym, c) wynik obliczeń udziału procentowego porów w stosunku do całej powierzchni

Fig. 3. The procedure for determining the concentration of pores and internal defects in padding welds using a software environment for padding welds EL-500 HB and EL-650 HB, where: a) X-ray in the selected cross-section b) the processed image as a result of assigning a binary color to individual colors of the surface in the software environment, $c$ ) the calculation of the percentage share of pores in the total surface

nym przekroju, zaś rysunek 3b przetworzony obraz graficzny uzyskany w wyniku przypisania poszczególnym kolorom powierzchni binarnie koloru w środowisku programowym. Ostatnim etapem było uzyskanie wyniku obliczeń udziału procentowego porów w stosunku do całej powierzchni, co zaprezentowano na rysunku 3c. Proces analizy procentowego udziału wad wewnętrznych napoin w stosunku do powierzchni całkowitej prowadzono na różnych, zdefiniowanych wcześniej odległościach od powierzchni czołowej napoiny. Umożliwiło to uogólnione i całościowe porównanie jakości wykonanych napoin.

Koncentrację porów i wad wewnętrznych napoin przedstawiono na rysunku 4. Najmniejszy średni procentowy udział wad w stosunku do powierzchni całkowitej otrzymano dla napoiny EL- 600 HB, który wyniósł 1,5\%. Maksymalny procentowy udział zarejestrowano na głębokości $3 \mathrm{~mm}$, który wyniósł $2 \%$. Natomiast minimalny procentowy udział zarejestrowano na głębokości $5 \mathrm{~mm}$, który wyniósł $1 \%$. Otrzymany dla napoiny EL-600 HB rozkład jest stosunkowo równomierny. Średni procentowy udział wad w stosunku do powierzchni całkowitej dla napoiny EL- $650 \mathrm{HB}$ wyniósł 4,38\%.

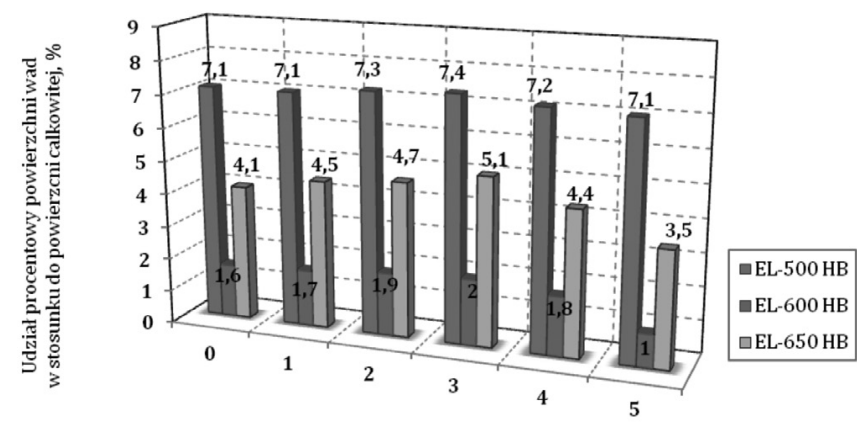

Polożenie względem powierzchni czołowej próbki napawanej, [mm]

Rys. 4. Koncentracja porów i wad wewnętrznych napoin

Fig. 4. The concentration of pores and internal defects in padding welds

Największy średni procentowy udział wad w stosunku do powierzchni całkowitej otrzymano dla napoiny EL- 500 HB, który wyniósł $7,2 \%$. Maksymalny procentowy udział zarejestrowano na głębokości 4 mm, który wyniósł 7,4\%. Najmniejsza koncentracja wad występuje w pobliżu materiału rdzenia oraz powierzchni napoiny. 


\section{Podsumowanie}

Zastosowana metoda tomografii komputerowej w porównaniu do tradycyjnej radiografii daje dużo większe możliwości diagnozowania i kontroli warstw napawanych oraz złączy spawanych. Zwiększa możliwości wykrywania wad i niezgodności spawalniczych, co umożliwia dokonanie oceny napoin i określenie ich przydatności eksploatacyjnej. Przeprowadzone badania dla napoin otrzymanych przy wykorzystaniu nowoczesnych litych drutów spawalniczych do napawania EL-500 HB, EL-600 HB, EL-650 HB, marki Most, pozwoliły ocenić jakościowy i ilościowy udział wad wewnętrznych. Najliczniejszymi wadami jakie zaobserwowano były pory. Najmniejszy średni procentowy udział wad w stosunku do powierzchni całkowitej otrzymano dla napoiny EL- 600 HB, który wyniósł 1,5\%. Natomiast największy średni procentowy udział wad w stosunku do powierzchni całkowitej otrzymano dla napoiny EL- 500 HB i wyniósł 7,2\%.

\section{Literatura}

[1] Kolbusz R., Tabor A., Wojciechowski W.: Napawanie elementów spiekanych materiałów konstrukcyjnych, Archives of Foundary, Vol. 6, Nr 21, str. 229-234, 2006.

[2] Pashechko M., Dziedzic K., Barszcz M.: Study of the structure and properties of wear-resistant eutectic Fe-Mn-C-B-Si-Ni-Cr coatings, Powder metallurgy and metal ceramics, nr 7-8, vol. 52, str. 469-476, 2013.

[3] Yüksel N., Sahin S.: Wear behavior-hardness-microstructure relation of $\mathrm{Fe}-\mathrm{Cr}-\mathrm{C}$ and $\mathrm{Fe}-\mathrm{Cr}-\mathrm{C}-\mathrm{B}$ based hardfacing alloys, Materials and Design Vol. 58, str. 491-498, 2014

[4] Badisch E., Katsich C., Winkelmann H., Franek F., Manish R.: Wear behavior of hardfaced Fe-Cr-C alloy and austenitic steel under 2-body and 3-body conditions at elevated temperature, Tribology International 43, str. 1234$-1244,2010$.

[5] Ratajczyk E.: Rentgenowska tomografia komputerowa (CT) do zadań przemysłowych, Pomiary Automatyka Robotyka, Vol. 5, str. 104-113, 2012.

[6] Yanga M., Xionga S.-M., Guoa Z.: Characterisation of the 3-D dendrite morphology of magnesium alloys using synchrotron X-ray tomography and 3-D phase-field modelling, Acta Materialia Vol. 92, str. 8-17, 2015.

[7] Hampel U.: X-ray computed tomography, Industrial Tomography, Systems and Applications, A volume in Woodhead Publishing Series in Electronic and Optical Materials, str. 175-196, 2015.

[8] Kułaszka, A. Chalimoniuk, M. Wieczorowski, M. Brzozowski, D.: The assessment of defects and discontinuities in weldings by means of computed tomography, Przegląd Spawalnictwa, vol. 87, Nr 12, s. 31-34, 2015. nictwa 2012, nr 2, str. 24-26. 